\title{
Crenosoma brasiliense sp. n. (Nematoda: Metastrongyloidea) parasitic in lesser grison, Galictis cuja (Molina, 1782) (Carnivora, Mustelidae) from Brazil, with a key to species of Crenosoma Molin, 1861
}

\author{
Fabiano M. Vieira ${ }^{1}$, Luís C. Muniz-Pereira ${ }^{2}$, Sueli de Souza Lima ${ }^{3}$, Antonio H.A. Moraes Neto ${ }^{4}$, \\ Pamela R. Gonçalves ${ }^{4}$ and José L. Luque ${ }^{5}$
}

\author{
${ }^{1}$ Curso de Pós-Graduação em Biologia Animal, Universidade Federal Rural do Rio de Janeiro, Seropédica, RJ, Brazil; \\ ${ }^{2}$ Laboratório de Helmintos Parasitos de Vertebrados, Instituto Oswaldo Cruz, FIOCRUZ, Rio de Janeiro, RJ, Brazil; \\ ${ }^{3}$ Departamento de Zoologia, Laboratório de Taxonomia e Ecologia de Helmintos, Universidade Federal de Juiz de Fora, Juiz de \\ Fora, MG, Brazil; \\ ${ }^{4}$ Laboratório de Inovações em Terapias, Ensino e Bioprodutos, Instituto Oswaldo Cruz, FIOCRUZ, Rio de Janeiro, RJ, Brazil; \\ ${ }^{5}$ Departamento de Parasitologia Animal, Universidade Federal Rural do Rio de Janeiro, Caixa Postal 74.508, CEP 23851-970, \\ Seropédica, RJ, Brazil
}

\begin{abstract}
This study describes Crenosoma brasiliense (Nematoda, Metastrongyloidea), a new species parasitic in bronchi and bronchioles of Galictis cuja (Molina) (Carnivora, Mustelidae) from Brazil. This species differs from other 11 species of Crenosoma by having a cuticular projection at the distal end of the spicules, forming a prominent blade at the tip of the spicule, a vulval cuticular appendage with a triangular shape and prominent vulval lips. There are no previous records of species of Metastrongyloidea in $G$. cuja or species of Crenosoma in South America. Therefore, the new species represents the first host record and first geographical record of species of Crenosoma in South America.
\end{abstract}

Keywords: Crenosoma, Galictis, wild carnivores, Brazil

Species of Crenosomatidae Schulz, 1951 (Nematoda, Metastrongyloidea) are parasites of the bronchi, frontal sinuses and veins of insectivorous and carnivorous mammals. This family currently contains five genera: Paracrenosoma Yun et Kontrimavichus, 1963, parasites of insectivorous mammals of the order Soricomorpha; Troglostrongylus Vevers, 1923, parasites of Felidae (Carnivora); Prestwoodia Anderson, 1978, parasites of Didelphis spp. (Didelphimorphia); Otostrongylus de Bruyn, 1933, parasites of Phocidae (Carnivora) species; and Crenosoma Molin, 1861, parasites of mammals of the orders Soricomorpha, Erinaceomorpha and Carnivora (Anderson 1978).

Crenosoma includes 11 valid species and is distinguished from other genera of the family Crenosomatidae by having a body cuticle with longitudinally striated crenated folds (Anderson 1978, Kontrimavichus et al. 1985). The species of this genus are distributed among hosts in Europe, Asia and North America (Skrjabin and Petrow 1928, Dougherty 1945, Yamaguti 1961, Craig and Anderson 1972, Addison 1978, Kontrimavichus et al. 1985, Jančev and Genov 1988, Torres et al. 2001, 2008). There have been no previous reports of Brazilian hosts until the present study.

Galictis cuja (Molina) (Carnivora, Mustelidae) is exclusive to South America and has been reported from Peru, Brazil, Paraguay, Chile, Uruguay and Argentina (Yensen and Tarifa 2003). In Brazil, this species occurs in several states and is found in the Cerrado (Brazilian savanna), Atlantic rainforest and southern grassland biomes (Emmons and Feer 1997, Cheida et al. 2006). Galictis cuja is a small, strictly terrestrial mammal with great agility and nocturnal activity, living in both forests and open areas, sheltered in burrows (Eisenberg 1989, Yensen and Tarifa 2003, Cheida et al. 2006). The diet of this carnivorous animal consists of other small mammals, reptiles, amphibians, birds and sometimes invertebrates (Eisenberg 1989, Yensen and Tarifa 2003, Cheida et al. 2006).

Nematodes of the superfamily Metastrongyloidea have not previously been reported from G. cuja from Brazil (Vicente et al. 1997, Vieira et al. 2008). The present study describes a new species of Crenosoma from this host species and presents the first report of this genus of nematode in a Brazilian host. 


\section{MATERIALS AND METHODS}

The nematodes were collected from the bronchi and bronchioles during three necropsies of Galictis cuja from the municipality of Juiz de Fora $\left(21^{\circ} 76^{\prime} \mathrm{S} ; 43^{\circ} 21^{\prime} \mathrm{W}\right)$, Minas Gerais State (MG), Brazil. The hosts examined were 'road kills' and were donated by the Regional Office of the Instituto Brasileiro do Meio Ambiente e dos Recursos Naturais Renováveis (IBAMA), in the municipality of Juiz de Fora, MG, between 2007 and 2010. The hosts were identified according to Yensen and Tarifa (2003) and Cheida et al. (2006).

The parasites were fixed AFA (70\% ethanol, 93 parts; $37 \%$ formalin, 5 parts; glacial acetic acid, 2 parts) for $48 \mathrm{hr}$, and preserved in $70 \%$ ethanol with $5 \%$ glycerin. For light microscopy studies, the nematodes were cleared in Amann's lactophenol (1:1:2:1-phenol : lactic acid : glycerin : water) in which they were kept during measuring and drawing. Drawings were made with the aid of a drawing tube attached to the Olympus BX41 light microscope (Olympus America Inc., Melville, New York). Measurements are given as ranges in micrometres $(\mu \mathrm{m})$, with the mean in parentheses.

Photomicrographs were made with Canon A3000IS camera (Canon Singapore Pte Ltd., Keppel Bay Tower, Singapore), with 10 megapixels of resolution, coupled to the Olympus BX41 light microscope. Some photomicrographs were made using a compound Olympus BX51 light microscope equipped with Nomarski Differential Interference Contrast (DIC) optics.

Identification and classification of the specimens to the generic level follow Chabaud (1974) and Anderson (1978). Holotype, allotype and paratypes are deposited in the Instituto Oswaldo Cruz Helminthological Collection (CHIOC), Rio de Janeiro, Brazil. Other paratypes are deposited in the Helminthological collection of the Institute of Parasitology (IPCAS), České Budějovice, Czech Republic.

\section{RESULTS}

\section{Crenosoma brasiliense sp. $\mathrm{n}$.}

Figs. 1-16

General: Specimens with cuticle with longitudinally striated crenated folds (Figs. 1, 8-11). Pronounced sexual dimorphism in which females are larger than males. Oral opening small and circular, surrounded by six elevations. Amphids not evident. Oesophagus claviform.

Male (holotype and two paratypes): Total length 3.6-3.9 (3.7) mm; width at level of base of oesophagus 140-155 (151); maximum body width 290-310 (301). Oesophagus 210-280 (253) long. Nerve ring 85-98 (93), and excretory pore 90-110 (101) from anterior extremity. Caudal bursa symmetrical and well developed, composed of rays that have one well developed globular apical papilla (Figs. 2, 3, 13). Ventral rays fused in proximal half of common stem. Ventral stem separated from lateral stem. Lateral rays with common stem, anterolateral ray separates first, diverging from other lateral rays in proximal third of stem; medio- and posterolateral rays only separate in distal half of stem (Figs. 2, 3). Mediolateral ray slightly larger than posterolateral ray. Externodorsal stem with only one ray. Dorsal ray robust and larger than externodorsal ray, and has at distal end two small lateral expansions and one apical papilla. Gubernaculum 80-90 (85) long, well developed, with distal and proximal ends narrow and tapered, and median region expanded, with central area rugged (Figs. 3, 4). Telamon not observed. Spicules similar in size and shape, 225-240 (233) long, with robust dorsal appendage which corresponds to one third of total size of spicule (Fig. 3). Distal end of spicule blade-shaped, composed of continued expansion that extends to ventral and dorsal end of spicule (Figs. 5, 14). Post-cloacal papillae absent.

Female (allotype and four paratypes): Total length 12.6-14.6 (13.7) mm; width at level of base of oesophagus 180-250 (215); maximum body width (in region of vulva) 410-480 (433). Oesophagus 270-340 (315) long. Nerve ring 94-98 (96), and excretory pore 100-110 (105) from anterior end. Vagina short, possesses two chitinized plates near to opening of vulva (Fig. 7). Vulva with well developed lips and with prominent triangular vulval cuticular appendage (Figs. 7, 12, 15, 16). Vulva is located in middle region of body, 3.9-4.0 (4.0) $\mathrm{mm}$ from anterior extremity. Tail sharply tapered, with prominent terminal papillae and two lateral subterminal papillae (Figs. 6, 12). Tail 160-180 (171) long. Ovoviviparous (Figs. 15, 16), with eggs containing first-stage larvae 50-72 (59) long and 35-50 (39) width.

Type host: Galictis cuja (Molina, 1782) (Carnivora, Mustelidae).

Site of infection: Bronchi and bronchioles.

Type locality: Juiz de Fora, Minas Gerais, Brazil, $21^{\circ} 76^{\prime} \mathrm{S}, 43^{\circ} 21^{\prime} \mathrm{W}$.

Prevalence: 1 of 3 hosts examined.

Intensity: 31 specimens.

Type specimens: Holotype male CHIOC no. 35813a, allotype female CHIOC no. $35813 \mathrm{~b}$ and one paratype male CHIOC no. $35813 \mathrm{c}$ and two paratypes females CHIOC no. $35813 \mathrm{~d}$ (preserved in $70 \%$ ethanol with $5 \%$ glycerin); one paratype male and two females (IPCAS No. N-993).

Etymology: The specific name was chosen because this species was the first Crenosoma described and reported in Brazil.

Remarks: The genus Crenosoma currently contains 11 valid species. The principal characteristics for the differentiation between species are the morphology of the bursa in males, the morphology of the spicules and the morphology of the vulva region in females.

Crenosoma brasiliense sp. $\mathrm{n}$. differs from Crenosoma hermani Anderson, 1962, C. vulpis (Dujardin, 1844), C. mephitidis Hobmaier, 1941 and C. goblei Dougherty, 1945 mainly by having the anterolateral ray of the bursa originating from the same common stem as the two other lateral rays (Hobmaier 1941, Dougherty 1945, Anderson 1962, Addison 1978). This characteristic is shared by seven other species from this genus: Crenosoma taiga Skr- 

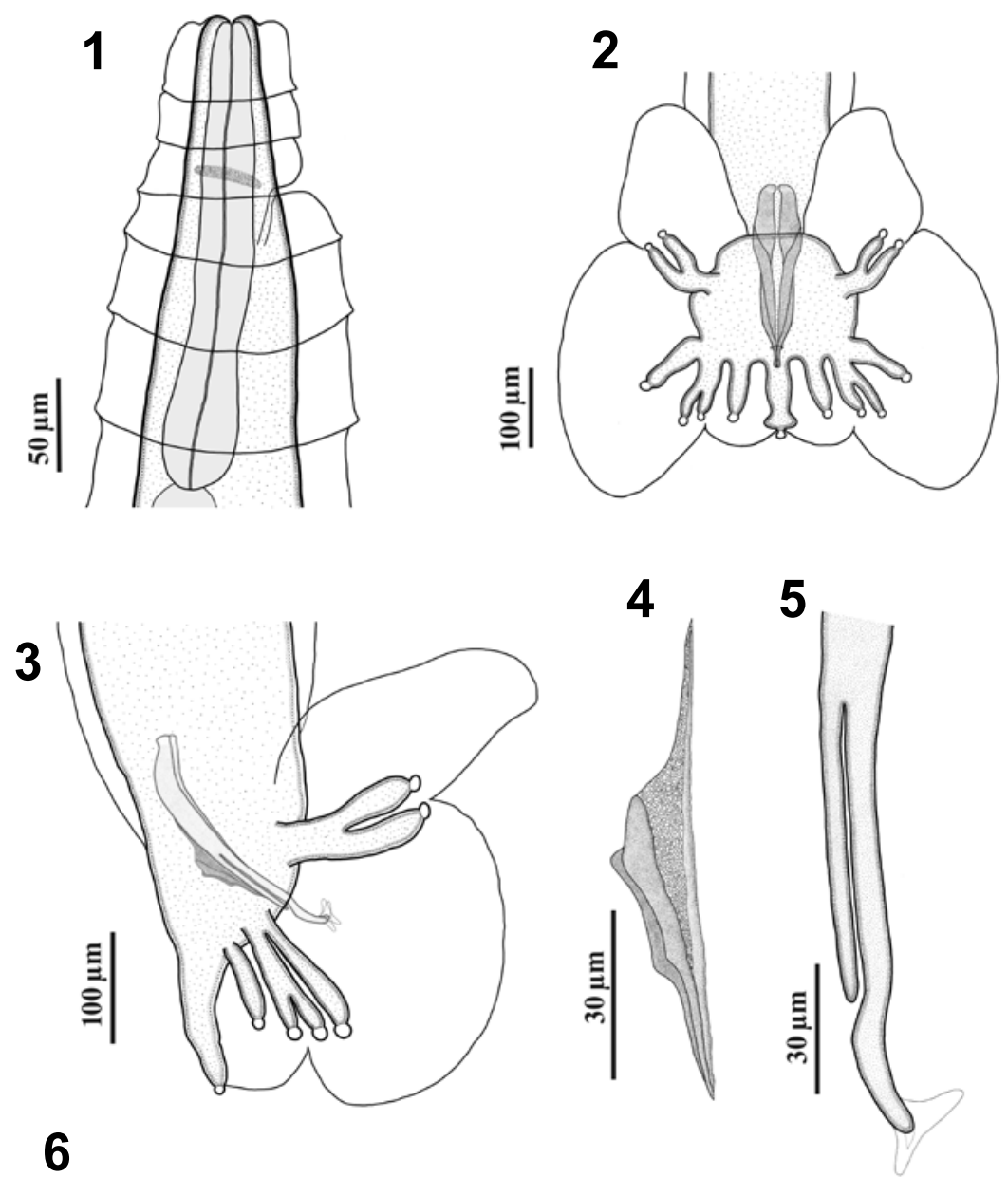

\section{6}

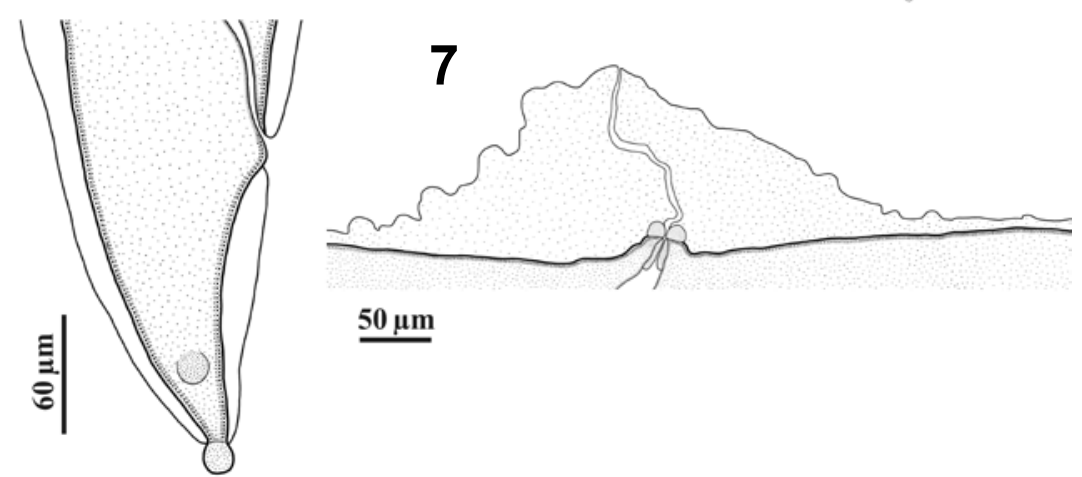

Fig. 1-7. Crenosoma brasiliense sp. n. 1 - male, anterior region, lateral view; $\mathbf{2}$ - male, caudal bursa, ventral view; 3 - male, caudal bursa, lateral view; $\mathbf{4}$ - male, gubernaculum, lateral view; $\mathbf{5}$ - male, distal end of spicule, lateral view; $\mathbf{6}$ - female, tail, lateral view; 7 - female, vulva and cuticular fringe - lateral view.

jabin et Petrow, 1928; C. petrowi Morozov, 1939; C. potos Buckley, 1930; C. striatum (Zeder, 1800); C. schachmatovae Kontrimavichus 1969; C. melesi; and C. lophocara Gerichter, 1951.

The ventral rays of the bursa in C. brasiliense originate from a common stem, differentiating this species from C. taiga, in which the ventral rays are independent (Skrjabin and Petrow 1928, Addison 1978). This characteris- tic is exclusive to $C$. taiga and has not been observed in other species of the genus.

Crenosoma brasiliense differs from $C$. petrowi by the absence of post-cloacal papillae in males. Addison (1978) reports one pair of post-cloacal papillae in C. petrowi, which is an exclusive character of this species.

Crenosoma potos has elongated, filiform rays of the bursa (Buckley 1930, Addison 1978). This character is 

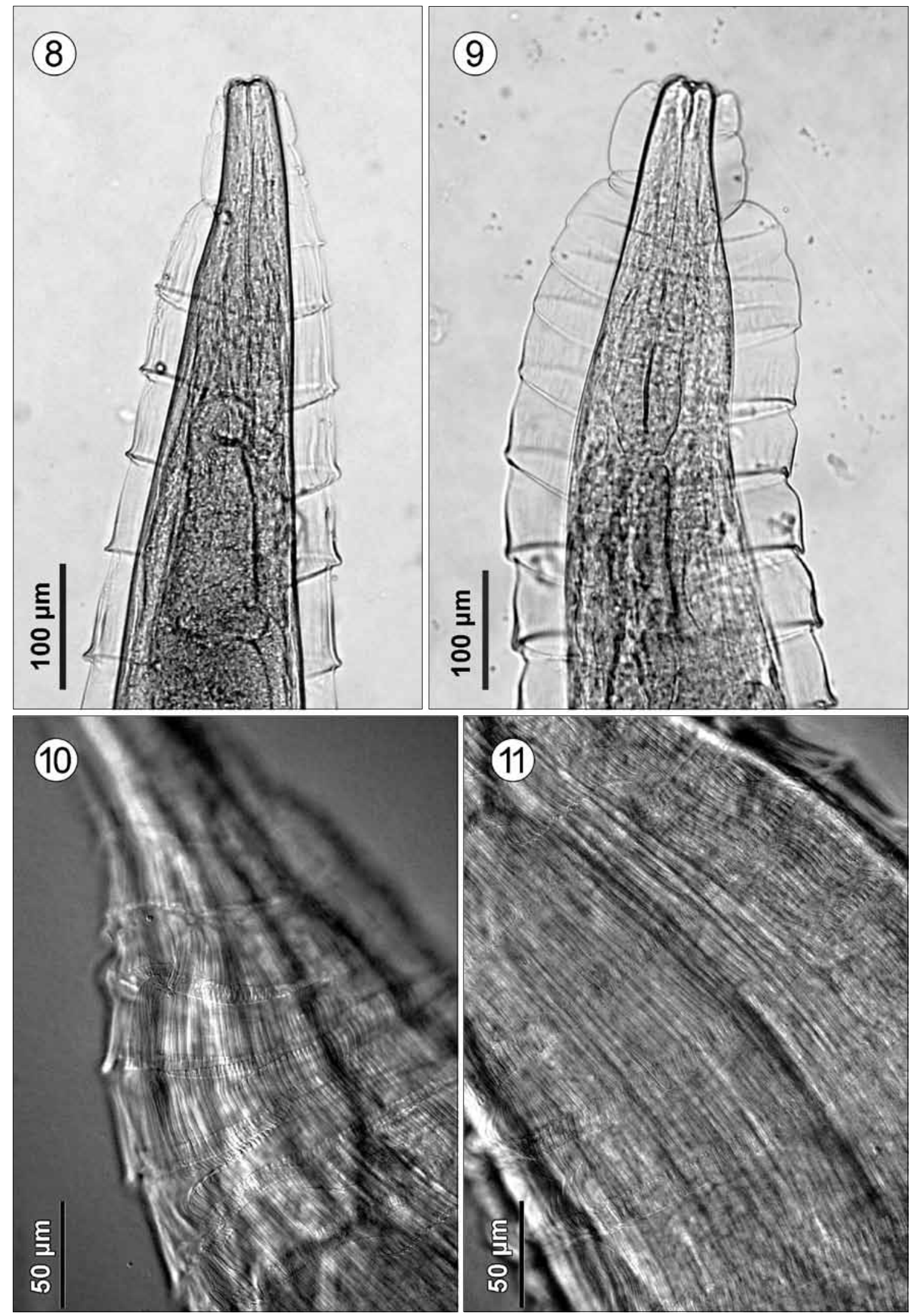

Fig. 8-11. Crenosoma brasiliense sp. n. 8 - male, anterior region, lateral view; light photomicrograph; 9 - female, anterior region, lateral view; light photomicrograph; 10 - female, anterior region, ventral view showing the longitudinal rows of cuticular striations; DIC photomicrograph; 11 - male, anterior region; lateral view showing the longitudinal rows of cuticular striations, DIC photomicrograph. 


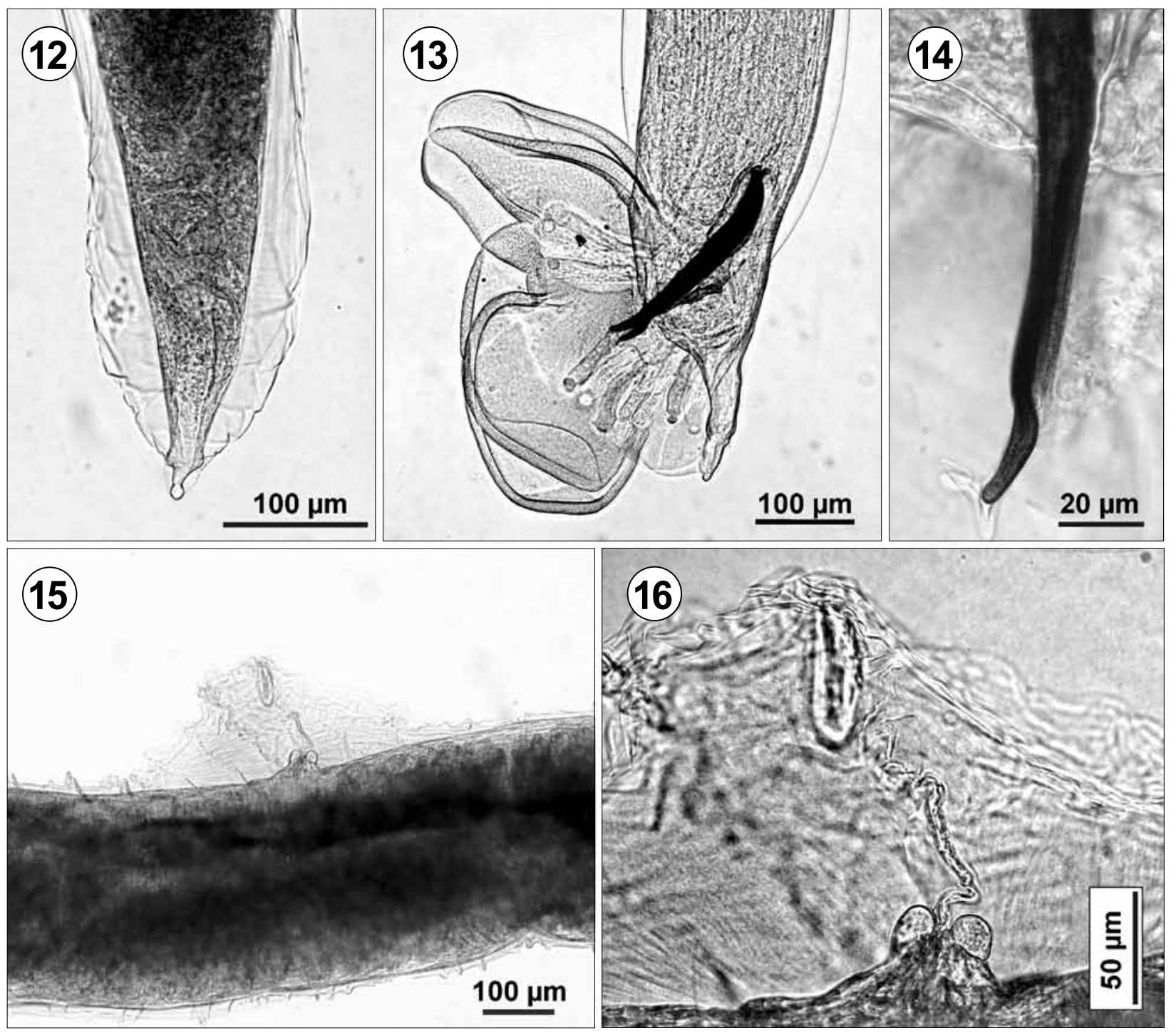

Fig. 12-16. Crenosoma brasiliense sp. n.; light photomicrographs. 12 - female, tail, ventral view; $\mathbf{1 3}$ - male, caudal bursa, lateral view. 14 - male, detail of the distal end of the spicule, lateral view; 15 - female, vulva and vulval cuticular appendage, lateral view; 16 - female, details of the vulva, vulval cuticular appendage and a first-stage larvae recently hatched, lateral view.

not observed in C. brasiliense or other species of this genus, which have shorter, robust rays of the bursa.

Crenosoma striatum, C. schachmatovae and C. melesi are distinguished from C. brasiliense and C. lophocara by the absence of a cuticular projection at the distal end of the spicules (Skrjabin and Petrow 1928, Baruš and Blažek 1971).

According to Gerichter (1951), C. lophocara males have a fine cuticular projection at the distal end of the spicules. However, this projection is not reported in the specimens of $C$. lophocara studied by Jančev and Genov (1988). The morphology of the cuticular projection at the distal end of the spicules in C. brasiliense has not been observed in other species of the genus. In C. brasiliense, this projection extends dorsally and ventrally beyond the distal end of the spicule, forming a prominent blade at the tip of the spicule (Figs. 5, 14). Crenosoma brasiliense females have a vulval cuticular appendage with a triangu- lar shape and prominent vulval lips (Figs. 7, 15, 16). According to the description given by Gerichter (1951), the vulval cuticular appendage of $C$. lophocara has an oval shape, but the author did not describe the vulval lips of the females of this species.

Besides the peculiar morphology of the distal end of the spicules, C. brasiliense differs from C. lophocara in other characters. The dorsal appendage on the spicule in C. lophocara corresponds to two thirds of the length of the spicule (Gerichter 1951); in C. brasiliense, the dorsal appendage on the spicule is equivalent to one third of the length of the spicule. The gubernaculum of these two species also has significant morphological differences. Both the proximal and distal ends of the gubernaculum are tapered and pointed in C. brasiliense (Fig. 4), whereas the proximal end of the gubernaculum is rounded and robust in C. lophocara (Gerichter 1951). 
Table 1. Comparative measurements (in $\mu$ m unless otherwise stated) of Crenosoma lophocara Gerichter, 1951 (according to Gerichter 1951) and Crenosoma brasiliense sp. $\mathrm{n}$.

\begin{tabular}{lccccc}
\hline & \multicolumn{3}{c}{ Crenosoma lophocara } & \multicolumn{2}{c}{ Crenosoma brasiliense sp. $\mathrm{n}}$. \\
\cline { 2 - 3 } \cline { 5 - 6 } & Male & Female & & Male & Female \\
\hline Total body length $(\mathrm{mm})$ & $5.6-6.3$ & $13.3-15.6$ & $3.6-3.9$ & $12.6-14.6$ \\
Maximum body width & $270-310$ & $420-440$ & $290-310$ & $410-480$ \\
Width at level of base of the oesophagus & - & - & $140-155$ & $180-250$ \\
Oesophagus length & $240-310$ & $310-330$ & $210-280$ & $270-340$ \\
Nerve ring & - & - & $85-98$ & $94-98$ \\
Excretory pore & - & - & $90-110$ & $100-110$ \\
Spicules & $330-370$ & - & $225-240$ & - \\
Gubernaculum & $110-120$ & - & $80-90$ & - \\
Vulva to the anterior end (mm) & - & - & - & $3.9-4.0$ \\
Tail & - & $160-200$ & - & $160-180$ \\
Eggs (length $\times$ width) & - & $56-67 \times 43-51$ & - & $50-72 \times 35-50$ \\
Spicule length/total body length ratio & $1: 17$ & - & $1: 15$ & - \\
\hline
\end{tabular}

Table 2. Species of Crenosoma with their geographical distributions and host orders.

\begin{tabular}{llll}
\hline Species & Continent & Host order & References* \\
\hline C. goblei Dougherty, 1945 & North America & Carnivora & $3,5,7$ \\
C. hermani Anderson, 1962 & North America & Carnivora & 6,7 \\
C. lophocara Gerichter, 1951 & Asia, Europe & Carnivora, Erinaceomorpha & $5,9,11$ \\
C. melesi Jančev et Genov, 1988 & Europe & Carnivora & $9,10,11$ \\
C. mephitidis Hobmaier, 1941 & North America & Carnivora & $2,3,5,7$ \\
C. petrowi Morozov, 1939 & Asia, Europe, North America & Carnivora & $1,3,4,7,11$ \\
C. potos Buckley, 1930 & North America & Carnivora & 8 \\
C. schachmatovae Kontrimavichus, 1969 Asia & Carnivora & 9 \\
C. striatum (Zeder, 1800) & Europe & Carnivora & $1,3,5$ \\
C. taiga Skrjabin et Petrow, 1928 & Asia & Carnivora & $1,3,5$ \\
C. vulpis (Dujardin, 1844) & Asia, Europe, North America & Carnivora & $1,3,5,8,9$ \\
C. brasiliense sp. n. & South America & Carnivora & present study \\
\hline
\end{tabular}

*References: 1 - Skrjabin and Petrow (1928); 2 - Hobmaier (1941); 3 - Dougherty (1945); 4 - Gerichter (1951); 5 - Yamaguti (1961); 6 - Anderson (1962); 7 - Craig and Anderson (1972); 8 - Addison (1978); 9 - Jančev and Genov (1988); 10 - Torres et al. (2001); 11 - Torres et al. (2008).

Morphometric differences are also found between C. brasiliense and C. lophocara (Table 1). The most evident differences are the larger size of the spicules, larger size of the gubernaculum and a greater spicule length/ total body length ratio in C. lophocara in comparison to C. brasiliense (Table 1).

\section{DISCUSSION}

Crenosoma species are parasites of the bronchi and bronchioles of mammals of the orders Carnivora and Erinaceomorpha (Yamaguti 1961, Craig and Anderson 1972, Kontrimavichus et al. 1985) (Table 2). The species of this genus have been reported from Europe, Asia and North America (Table 2), but have not previously been found in Brazil or other parts of South America (Table 2). The only genus of Crenosomatidae registered in Brazil is Troglostrongylus Vevers, 1923, the species of which are parasites of Brazilian Didelphimorphia (Vicente et al. 1997).

Several keys to the identification of species of Crenosoma have been proposed. Wallace (1941) proposed a key to the differentiation of six species of the genus that were valid at the time, including C. microbursa Wallace, 1941, described by the author and considered a synonym of C. mephitidis by Craig and Anderson (1972). A revision of this genus by Dougherty (1945) reported eight valid species of Crenosoma at the time and also proposed a species identification key. Craig and Anderson (1972) carried out a comparative study of species of Crenosoma from mammals in North America and proposed some synonymies and transferred some species to other genera.

The most recent proposal of a key for species of Crenosoma was drafted by Kontrimavichus et al. (1985), but the authors divided the key by groups of hosts and did not consider some synonyms proposed by Craig and Anderson (1972). In the present study, we propose an updated key for species of Crenosoma considering the synonyms proposed by Dougherty (1945) and Craig and Anderson (1972) as well as the morphological data on the species studied by Baruš and Blažek (1971), Addison (1978), and Jančev and Genov (1988). 


\section{Key to species of Crenosoma Molin, 1861}

1 Anterolateral ray of the bursa separate from other two laterals rays. Medio- and posterolateral rays arise from a common stem 9

- Three lateral rays of the bursa arise from a common stem 2

2 Ventral rays of the bursa do not arise from a common stem ........................................................... C. taiga

- Ventral rays of the bursa arise from a common stem.. ... 3

3 Male bursa with one pair of post-cloacal papillae C. petrowi

- Male bursa without post-cloacal papillae ... 4

4 Rays of bursa very elongated and filiform ... C. potos

- Rays of the bursa slightly elongated and robust ...... 5

5 Spicules without cuticular projection at the distal end

..................................................................... 7

- Spicules with cuticular projection at the distal end .. 6

6 Cuticular projection at the distal end of spicules poorly developed. Vulval cuticular appendage with oval shape C. lophocara

- Cuticular projection at the distal end of spicules well developed. Vulval cuticular appendage triangular ..... Crenosoma brasiliense sp. $\mathrm{n}$.

7 Females with vulval cuticular appendage ............... 8

- Females without vulval cuticular appendage C. schachmatovae

8 Vulval cuticular appendage well developed, oval ...... C. melesi

- Vulval cuticular appendage poorly developed, tubular C. striatum
9 Females with vulval cuticular appendage 10

- Females without vulval cuticular appendage C. hermani

10 Vulval cuticular appendage well developed 11

- Vulval cuticular appendage poorly developed C. mephitidis

11 Dorsal appendage of spicule robust; short spicule .....

- Dorsal appendage of spicule delicate; long spicule .... C. vulpis

Records of helminths in G. cuja from Brazil are restricted to the occurrence of Pachysentis gethi (Machado Filho, 1950) (Acanthocephala, Oligacanthorhynchidae), Dioctophyme renale (Goeze, 1782) (Nematoda, Dioctophymatoidea) and Dirofilaria sp. in hosts from the state of Rio de Janeiro (Barros et al. 1990, Vieira et al. 2008). Nematodes of the genera Cruzia Travassos, 1917 (Ascaridida, Kathlaniidae), Dirofilaria Railliet et Henry, 1910 (Spirurida, Onchocercidae), Gnathostoma Owen, 1836 (Spirurida, Gnathostomatidae) and Lagochilascaris Leiper, 1909 (Ascaridida, Ascarididae) have been recorded in G. cuja from Paraguay (Yensen and Tarifa 2003). However, there are no previous records of species of Metastrongyloidea in this host species or any species of Crenosoma in South America. Therefore, the present study provides the first host record and first geographical record of species of Crenosoma in South America.

Acknowledgments. Fabiano M. Vieira was supported by a doctoral fellowship from REUNI/UFRRJ (Programa de Apoio ao Plano de Reestruturação e Expansão das Universidades Federais, Brazil); José L. Luque was supported by a research fellowship from CNPq (Conselho Nacional de Pesquisa e Desenvolvimento Tecnológico, Brazil).

\section{REFERENCES}

Addison E.M. 1978: Crenosoma spp. (Nematoda: Metastrongyloidea) from black bears, Ursus americanus, of central Ontario. Can. J. Zool. 56: 1993-1997.

Anderson R.C. 1978: No. 5. Keys to genera of the Superfamily Metastrongyloidea. In: R.C. Anderson, A.G. Chabaud and S. Willmott (Eds.), CIH Keys to the Nematode Parasites of Vertebrates. Commonwealth Agricultural Bureaux, Farnham Royal, UK, pp. 1-40.

Anderson R.C. 1962: The systematics and transmission of new and previously described metastrongyles (Nematoda: Metastrongylidae) from Mustela vison. Can. J. Zool. 40: 893-920.

Barros D.M., Lorini M.L., Persson V.G. 1990: Dioctophymosis in the little grison (Galictis cuja). J. Wildl. Dis. 26: 538-539.

Baruš V., BlažEK K. 1971: The life cycle and the pathogenicity of the nematode Crenosoma striatum. Folia Parasitol. 18: 215-226.
Buckley J.J.G. 1930: On a lungworm, Crenosoma potos, n. sp., from the Kinkajou, Potos flavus (Schreber). J. Helminthol. 8: 229-238.

Chabaud A.G. 1974: No. 1. Keys to subclasses, orders and superfamilies. In: R.C. Anderson, A.G. Chabaud and S. Willmott (Eds.), CIH Keys to the Nematode Parasites of Vertebrates. Commonwealth Agricultural Bureaux, Farnham Royal, UK, pp. 6-17.

Cheida C.C., Nakano-Oliveira E., Fusco-Costa R., RochaMendes F., Quadros, J. 2006: Capítulo 08 - Ordem Carnivora. In: N.R. Reis, A.L. Peracchi, W.A. Pedro and I.P. Lima (Eds.), Mamíferos do Brasil. Editora Universidade Estadual de Londrina, Londrina, Brasil, pp. 231-276.

Craig R.E., Anderson R.C. 1972: The genus Crenosoma (Nematoda: Metastrongyloidea) in New World mammals. Can. J. Zool. 50: 1555-1561. 
Dougherty E.C. 1945: A review of the genus Crenosoma Molin, 1861 (Nematoda: Trichostrongylidae) - its history, taxonomy, adult morphology and distribution. Proc. Helminthol. Soc. Wash. 12: 45-62.

EISENBERG J.F. 1989: Mammals of the neotropics. Vol 1. The Sourthen Cone. University of Chicago Press, Chicago, 449 pp.

Emmons L.H., Feer F. 1997: Neotropical Rainforest Mammals: a Field Guide. University of Chicago Press, Chicago, $307 \mathrm{pp}$.

Gerichter C.B. 1951: Two new lung nematodes from Near-East mammals. Parasitology 41: 184-188.

Hobmaier M. 1941: Description and extramammalian life of Crenosoma mephitidis n. sp. (Nematoda) in skunks. J. Parasitol. 27: 229-232.

JANČEV J., Genov T. 1988: On the morphology and taxonomy of species from the genus Crenosoma Molin, 1861 (Nematoda: Crenosomatidae) in Bulgaria. Helminthology 25: 45-62.

Kontrimavichus V.L., Delyamure S.L., Boev S.N. 1985: Metastrongyloids of domestic and wild animals. Fundamentals of Nematology. Volume 26. English Translation of Osnovy Nematodologii, Tom XXVI, Metastrongyloidei Domashnikh i Dikikh Zhivotnykh, Nauka Publishers, Moscow. Oxonian Press Pvt. Ltd., New Delhi, India, 298 pp.

Received 9 April 2012
Skrjabin K.I., Petrow A.M. 1928: A description of the genus Crenosoma Molin, 1861 (Metastrongylidae, Nematoda). Parasitology 20: 329-335.

Torres J., Miquel J., Fournier P., Fournier-Chambrillon C., Liberge M., Fons R., Feliu C. 2008: Helminth communities of the autochthonous mustelids Mustela lutreola and M. putorius and the introduced Mustela vison in south-western France. J. Helminthol. 82: 349-355.

Torres J., Miquel J., Motjé M. 2001: Helminth parasites of the Eurasian badger (Meles meles L.) in Spain: a biogeographic approach. Parasitol. Res. 87: 259-263.

Vicente J.J., Rodrigues H.O., Gomes D.C., Pinto R.M. 1997: Nematóides do Brasil. Parte V: Nematóides de mamíferos. Rev. Bras. Zool. 14: 1-452.

Vieira F.M., Luque J.L., Muniz-Pereira L.C. 2008: Checklist of helminth parasites in wild carnivore mammals from Brazil. Zootaxa 1721: 1-23.

Wallace F.G. 1941: Crenosoma microbursa, n. sp., from the skunk. Proc. Helminthol. Soc. Wash. 8: 58-60.

Yamaguti S. 1961: Systema Helminthum. Vol. III. The Nematodes of Vertebrates. Interscience Publishers Inc., New York, 1125 pp.

Yensen E., Tarifa T. 2003: Galictis cuja. Mamm. Species 728 : $1-8$.

Accepted 27 July 2012 